\title{
Ecosystem Services for Planning: A Generic Recommendation or a Real Framework? Insights from a Literature Review
}

\author{
Silvia Ronchi
}

check for updates

Citation: Ronchi, S. Ecosystem Services for Planning: A Generic Recommendation or a Real Framework? Insights from a Literature Review. Sustainability 2021, 13, 6595. https://doi.org/10.3390/ su13126595

Academic Editor: Åsa Gren

Received: 28 April 2021

Accepted: 7 June 2021

Published: 9 June 2021

Publisher's Note: MDPI stays neutral with regard to jurisdictional claims in published maps and institutional affiliations.

Copyright: (C) 2021 by the author. Licensee MDPI, Basel, Switzerland. This article is an open access article distributed under the terms and conditions of the Creative Commons Attribution (CC BY) license (https:/ / creativecommons.org/licenses/by/ $4.0 /)$.
Department of Architecture and Urban Studies, Politecnico di Milano, 20133 Milano, Italy; silvia.ronchi@polimi.it

\begin{abstract}
Recently, the concept of Ecosystem Services (ESs) has undergone a process of mainstreaming. It has been promoted in multiple policy documents and investigated in a growing number of studies addressing the functioning, assessment and management of ESs. Despite a general recommendation to integrate ESs into planning processes, this step remains highly critical yet far from complete. This paper explores the feasibility of the recommended uses of ESs for planning purposes by examining the needs of planners and decision-makers. A systematic literature review was conducted analysing different studies to overcome the limited adoption of ESs in planning verifying their operationalisation for planning practices. The paper classifies different purpose(s) assigned to ESs supporting the planning process. The results show that few experiments have adopted a step-by-step procedure facilitating the integration of ESs into planning and highlighting their added value in each phase of the planning process. In these cases, an ES-based Green Infrastructure has allowed for their integration into planning, also adopting a multi-scale spatial dimension. More practical experiments on how a planning process works are needed to operationalise the ESs concept for planning purposes, also reinforcing the role of the Strategic Environmental Assessment that is still marginal.
\end{abstract}

Keywords: planning process; multi-scalarity; green infrastructures; ecosystem services purposes; decision support

\section{Introduction}

In recent years, the concept of Ecosystem Services (ESs) has gained attention in several disciplines, becoming the focus of an intense academic debate around its use in the decisionmaking process for stakeholder awareness both in planning and policy design, and in the promotion of sustainable development [1].

The potential and opportunities of the ESs approach to support strategic decisions have increasingly been investigated in many scientific papers; indeed, they have been the focus of numerous steering documents and guidelines for international organisations (such as IUCN-International Union for Conservation of Nature, UNEP-United Nations Environment Programme, and IPBES-Intergovernmental Science-Policy Platform on Biodiversity and Ecosystem Services [2-4]), and the object of various attempts to understand the stage of ESs integration in planning and to define possible methods or tools for their use in planning and policy documents (amongst the many examples: [1,5-8]).

During the years, the concept of ESs has often been associated with planning. For example, de Groot et al. [9] consider ESs to be a potential tool for strategic spatial planning as well as landscape planning and design, and Galler et al. [10] recognise that "the ESs approach adds new information and perspectives to traditional information, its presentation, and its contribution to decision-support in landscape and spatial planning". ESs are seen as a concept that could aid in planning and policymaking as a basis for supporting the assumption of decisions, as it provides an umbrella for coordinating different policy instruments in a more strategic and synergistic manner [11].

The anthropocentric perspective of ESs provides additional arguments for addressing their integration into planning as a key aspect for convincing decision-makers that human 
well-being is closely linked to the quality of the ecosystem and that, beyond the purely economic and monetary perspective, there is also a need to take health, social relations, and indigenous and local knowledge and perceptions into consideration [3,12]. ESs are a useful tool for identifying and communicating the benefits and value of nature, especially in urban areas [13-15]. Urbanisation is a critical driver that poses many challenges to the health of ESs through the degradation of green areas, increases in impervious surfaces, population growth, and the growing intensity of waste discharge and nutrient loading [16,17]. Spatial planning may result in urban development contributing to the protection of natural capital and its associated benefits, preventing negative impacts on service-providing units, enhancing their provision of ESs, and weighing up the benefits and drawbacks of different options for development $[15,18]$. For all these reasons, spatial planning is considered a key policy instrument for the improvement of ESs, with decisions regarding land-use that have clear and direct effects on the provision of a range of ESs.

As such, a growing body of literature has emerged calling for the integration of ESs into planning, with the aim of ensuring a high level of environmental protection (e.g., [13,18-20]). Despite a common agreement on the need to integrate ESs into planning, few experiments concern their operationalisation for planning purposes, whilst many barriers to their integration still remain [7,21,22]. The limits of ESs integration into planning have been acknowledged on many occasions by multiple authors: some argue that there is a lack of guidance on how ESs could inform decisions, as well as at what point in the planning process the ESs concept should be applied (e.g., $[15,21])$. Others claim that the ESs concept is not clear or widely understood enough amongst planning practitioners, resulting in a low level of engagement from the key stakeholders in developing these policies (e.g., [21,23,24]). Indeed, yet others say that implicit references to ESs can be only found where plans refer to the benefits provided by nature (e.g., $[1,25,26])$.

Moreover, various recent studies and experiences have demonstrated that ESs provision via spatial planning has been advocated through Green Infrastructures (GI) [27-29], suggesting that the GI concept is a valuable tool for "translating" the complex topic of ESs into more appropriate terms, better suited to the language traditionally adopted in urban planning [30]. A GI is defined as a "network of natural and semi-natural areas with other environmental features that is supposed to deliver ecosystem services" [31] and as "a design vision that translates [a] planning strategy into physical reality while heeding the ecological and cultural characteristics of a particular locale-whether a region or an individual building" [32]. GI can mitigate the adverse effects of climate change, by, for example, regulating urban temperatures, avoiding the heat island effect, and reducing storm-water runoff, limiting flood events, and offering recreational space opportunities. Planning can play a key role in adopting GI for climate adaptation as a strategy to respond to global warming [33]. Recent years have seen a small yet steadily growing body of studies on how GI experiences based on ESs have been integrated into planning (e.g., [27,34]).

This paper seeks to contribute to these efforts by conducting a literature review on recent studies in which ESs and planning are the main focus. The aim is not to explore the limitations that preclude the integration of ESs into planning, but rather to investigate the different proposals suggested for overcoming these limitations, verifying whether they are indeed laudable recommendations that are difficult to implement or whether they are feasible enough to be of interest to planners for planning practices.

This study intends to discover why, despite the numerous proposals for integrating ESs into planning, this process is still so uncommon and limited to a handful of good practices and experiments, questioning the appropriateness of the role played by ESs in planning practice. The research paper explores the validity of the proposals for integrating the concept of ESs into planning and whether or not they are of interest to planners and decision-makers. A literary review of studies published in the last three years was conducted to verify the feasibility of individual proposals for integrating ESs into the planning process, shedding light on the intricacies of the obstacles to operationalising ESs in planning practices. 
Integration into the planning process entails ESs being used in different phases, taking on a key role for planning purposes, namely [8,35-37]:

1. the preparatory phase, i.e., the identification of the problems and opportunities that lead to specific planning issues and the establishment of planning goals;

2. the investigation phase, i.e., the creation of an initial knowledge assessment of the context, collecting information on the physical, biological and social elements that constitute the planning area;

3. the feasibility phase (the planning one), i.e., a first draft of the detailed studies aiming to understand the complex relationships between human values, environmental opportunities and constraints;

4. the alternative scenarios phase, i.e., the development of different scenarios for the future management of the area, measuring and assessing their possible impacts;

5. the formal planning phase, i.e., the drafting of land-use plans, zoning, building regulation plans;

6. the implementation phase, i.e., the application of various strategies, tactics and procedures to reach the established goals;

7. the operational phase, i.e., the monitoring and management strategies that aim to guarantee the effectiveness of the planning decisions.

The next section describes the methods used to conduct the review. Section 3. presents the results of said review, which are then discussed in Section 4. The concluding section provides some possible future research challenges.

\section{Materials and Methods}

As previously explained in the introduction, this paper aims to assess and classify the proposals made by studies and research on possible ways for ESs to be integrated into planning, verifying whether or not they are functional to the planning practice and, consequently, if they can be applied in the process of drafting a plan or programme.

A literature review was conducted using the electronic databases of Science Direct and Scopus, searching for the combination of keywords: "ecosystem services AND planning" in the titles of scientific articles or chapters of books published in English. The terms used for the search are intentionally generic, including any type of ES (regulating, provisioning, supporting and cultural $[38,39]$ ) and planning type (landscape, territorial, local, urban, regional, marine, etc.), in order not to focus on a certain ES and, consequently, limit the integration of ESs to a specific planning type or instrument of governance. Other combinations of keywords were evaluated to carry out the research, for example, using a specific type of planning but this could preclude the inclusion of many studies therefore a more generic search was chosen.

The search was conducted on 4 December 2020, selecting articles published in the last three years $(2018,2019,2020)$; after the removal of duplicates and an initial reading, ten papers were rejected due to planning being a less prominent subject and not the core of the research, the search returned 70 articles and chapters for analysis: 31 from 2020, 15 from 2019 and 24 from 2018. The publications were selected on the basis of the explicit presence of proposals or suggestions (methodological and/or operative) for the integration of ESs into planning.

For each publication, the following research questions were posed, guiding the literature review process (Figure 1):

1. What purpose(s) are assigned to ESs in their role of supporting the planning process? [Q1] 


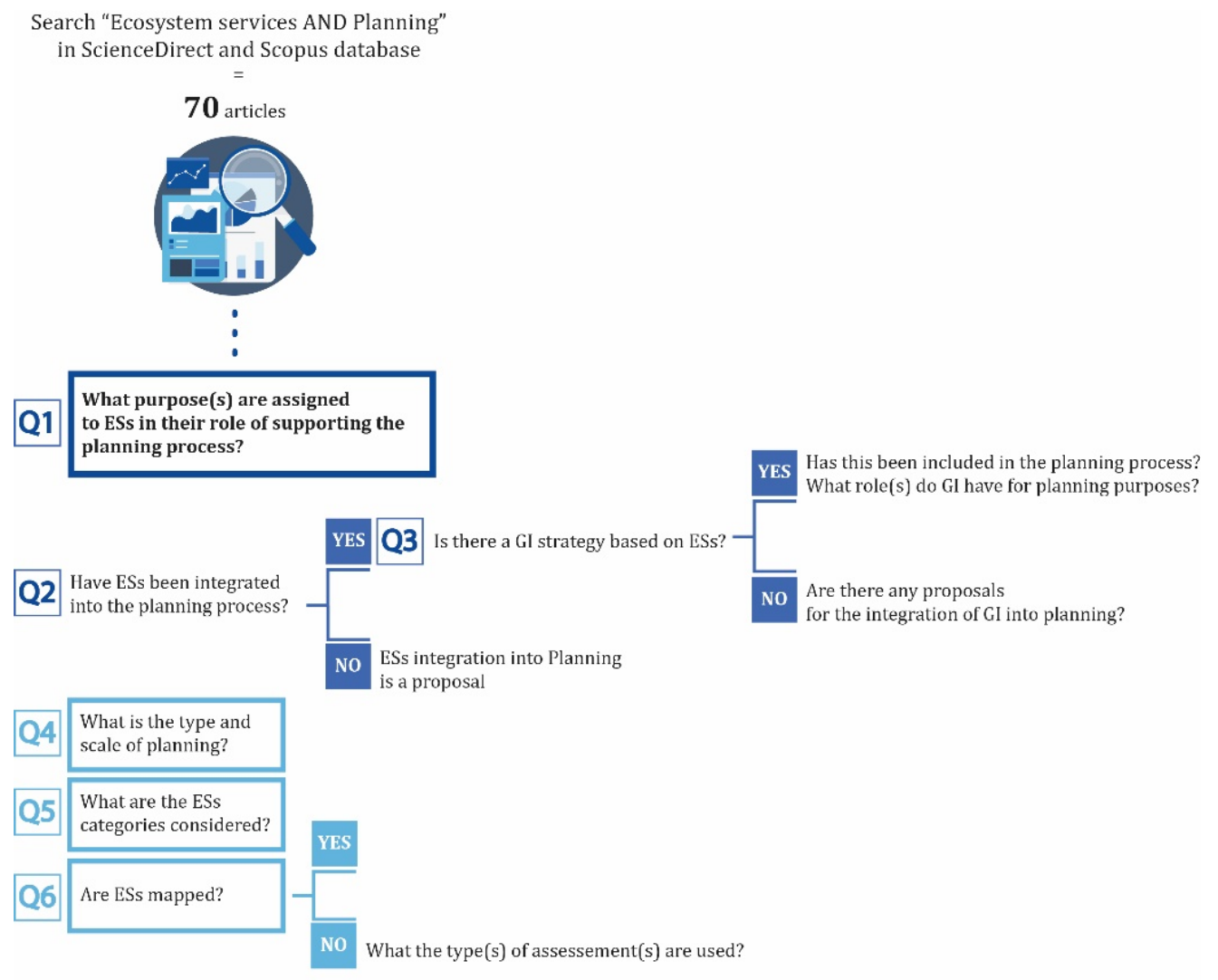

Figure 1. The methodology adopted for the systematic literature review.

This is the key question of the paper, aiming to investigate how different lines of research propose to adopt ESs in planning and what the added value of ESs is for planning purposes.

The second group of questions aimed to analyse the operationalisation of the aforementioned purposes assigned to ESs for the planning process, and whether or not these proposals have allowed for their integration into the planning process:

2. Have ESs been integrated into the planning process? [Q2]

- If NO, it can be assumed that the integration of ESs into planning is merely a proposal, therefore, the purpose(s) assigned to ESs have already been investigated answering question 1 ;

- If YES, the following questions arise:

3. Is there a GI strategy based on ESs? [Q3]

- If YES: Has this been included in the planning process? What role(s) do GI have for planning purposes?

- If NO: Are there any proposals for the integration of GI into planning? What are they?

In addition, some other issues were also investigated, namely:

4. The type of planning, checking whether a single most prevalent planning type for the integration of ESs exists [Q4];

5. The categories of ESs, highlighting the presence of a specific category of ESs that may be more commonly considered than others for planning purposes [Q5];

6. ES mapping [Q6]. The addition of this aspect could serve to verify whether the current studies are still mostly focused on the spatial modelling of ESs or whether, in addition to these important assessments, an extra step has been taken by trying to integrate them into the planning process using the considerations derived from their mapping. 


\section{Results}

\subsection{Overview of the Purposes Assigned to ESs for Their Integration into Planning}

Articles included in the literature review were initially catalogued according to the key question, to understand what purpose(s) were assigned to ESs in the planning process and why planners should adopt ESs and what added value ES-based planning offered.

Results show that the articles often have more than one purpose assigned to ESs for planning. In answer to the research questions, the study has identified five categories of possible purposes for ESs to facilitate their integration into the planning process and for planning goals (Figure 2):

1. ESs for supporting the decision-making process

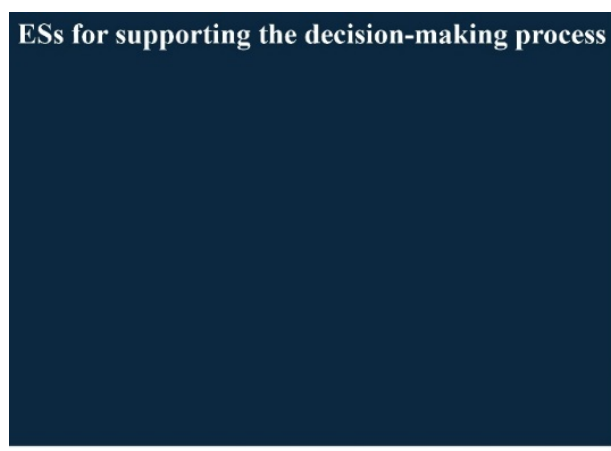

ESs as a new knowledge base
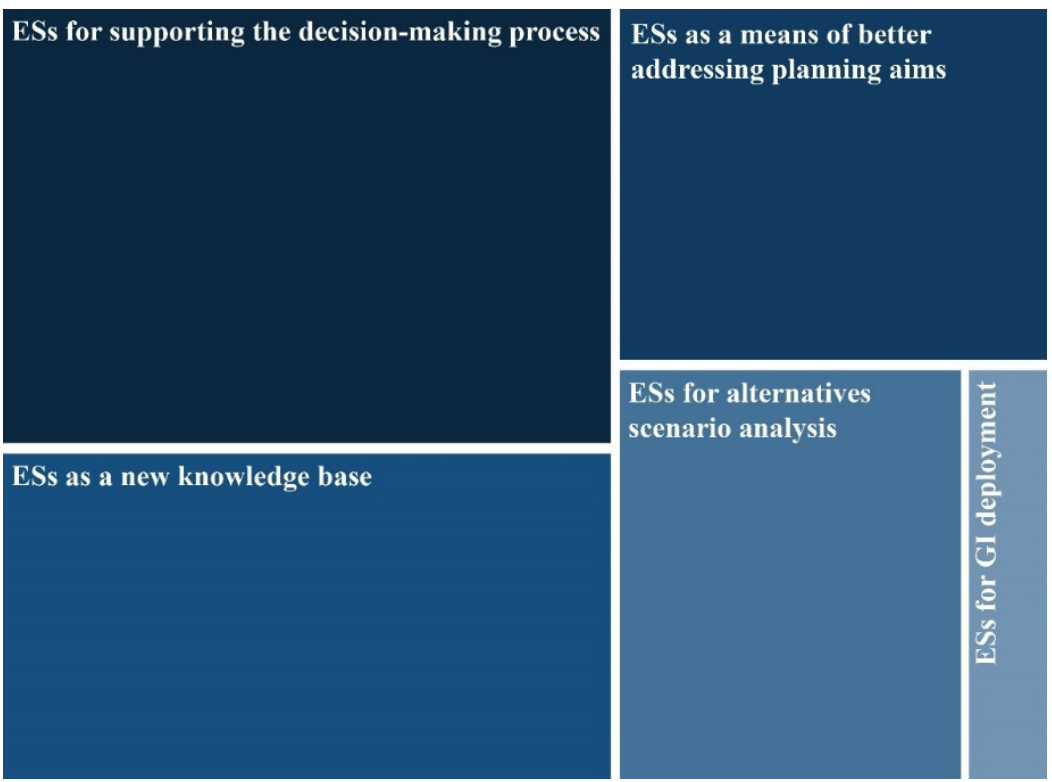

Figure 2. TreeMap with the distribution of the five categories of ESs purposes in the planning process, as assigned by the articles included in the literature review (The figure was developed using "RAWGraphs" which is a web interface to create custom vector-based visualisations, and refined with Adobe Illustrator 2021 (Adobe Systems Inc., San Jose, CA, USA)).

The first purpose attributed to ESs and mentioned in more than half of the research concerns the support they provide for the decision-making process. The use of the concept of ESs is perceived as an element that can improve and facilitate discussion between stakeholders, planners, and managers [40] as a "more collaborative method" [41] that is "crucial to perform[ing] decision-relevant assessment[s] and support[ing] sustainable regional governance at multiple scales" [42].

Although generally speaking, the language of ESs is hard to understand and difficult to adapt to public discourse - as highlighted in the survey developed by Peña et al. [24] various articles argue for the potential added value of ESs "to improve stakeholder engagement" [43], "to simplify and better understand the nature of a geographic phenomenon" [44], and "for informing, communicating and facilitating consensus building among different actors because it provides a basis for multi-sectoral and interdisciplinary collaboration" [45].

ESs are seen as "useful information to be incorporated into the planning process and a common language that facilitates communication with and between researchers/technicians, decision-makers, [and] stakeholders" [46]. Again, it is acknowledged that ESs can create an "analytical framework which puts stakeholders, their land-use/management choices, their impact on ESs and responses at the centre" [47].

2. ESs as a new knowledge base 
Meanwhile, a significant number of articles (28 in total) are devoted to the contribution of ESs in providing new information and knowledge to lend weight to environmental issues in planning. Most of these articles frame ESs as a valuable means of "setting the scene", formulating an environmental framework that takes ESs into account that proves helpful in the preparatory phase of a planning process, also using ESs mapping and assessment to demonstrate how the spatial distribution of ESs can support the decision-making process by establishing planning priorities.

Some of them focus on the added value of ESs as a knowledge base, using an assessment framework to make soil ESs understandable and usable by actors of territorial planning [42], to establish links between socio-economic variables and ecosystem service provision for urban planning [48], to understand the impact of planning and management decisions [49,50], or to produce useful knowledge for local practitoners and operationalizing the full spectrum of the ecosystem service concept for strategic sustainability planning and related decision-support contexts [51].

3. ESs as a means of better addressing planning aims

Other articles (18 in total) address the idea of adopting ESs to improve the consideration of ecological components in planning and to better orient its environmental goals. A reduced consideration of some environmental issues is probably recognised in planning and the issue of ESs is seen as an opportunity to solve this lack. Some ultimate aims are to improve sustainability of nature management [52], reorient land-use planning practices to maximise ESs delivery [53], develop an effective planning strategy for ecosystem protection [54], enable more resource-efficient urban planning [55]. The planning goals that can be achieved by adopting an ESs approach are quite varied, but there is a marked intention to improve planning on ESs provision as a way of protecting natural capital. This purpose assigned to ESs is particularly useful for the preparatory phase in establishing the planning goals.

4. ESs for alternative scenario analysis

A significant segment of the research (16 articles in total) is dedicated to supporting planning in the alternative scenarios phase. Assessing ESs is considered as a way of devising possible future scenarios that are useful for gaining a better understanding-in advance- of the implications of certain planning decisions on ESs trends (and, consequently, on human well-being). ESs are seen as a possible tool for performance-based planning that can assess future urban transformations based on ESs performance [56], prioritise conservation areas by creating various planning scenarios [57], support the definition of future urban management and land-use planning, define scenarios for conservation [1] and "provide a robust approach to facilitate sustainable urban development [ . . ] and help avoid negative impacts on service providing units, enhance their provision of ecosystem services, and weigh the benefits and drawbacks of different development options" [58].

5. ESs for GI deployment

A handful of experiments reveal that ESs are considered important for developing a multifunctional GI strategy. The articles are not numerically relevant ( 8 in total) but the contents are very innovative. In particular, one research paper is dedicated to the province of Barcelona and defines key areas for multifunctional GI planning based on biodiversity, ecosystem functions, and ESs supply and demand [34]. This very clearly demonstrates the added value of ESs arguing that a "knowledge base obtained from traditional ESs mapping can be complemented, mainstreaming GI governance and planning, and empowering ESs beneficiaries" [34].

A second article focuses on the Basque Country, where a proposal for a regional GI was formulated by identifying the multifunctional areas that provide ESs; an ESs assessment was developed and taken into account at the beginning of the planning process, in part as a way of gradually introducing the technical and specific terms involved, thus facilitating a shared language in order to encourage "science-based decision-making/management" [24]. 
The last interesting experiment concerns GI deployment based on different areas' potential capacity to provide ESs and the related trade-offs developed in the Galicia region. "The ESs provision potential maps give basic information for decision-making on spatial planning and land management by locating the areas that provide each ES and quantifying these services. The results of ESs assessment can be applied in multiple land management or planning processes, from the protection of core areas of GI to ecosystem restoration" [59].

Besides these, a GI strategy was also developed in other studies [60-64], proposing interesting and innovative methodologies which recognise ESs as a "useful concept in assessing and planning for the multiple uses of urban green infrastructure" [63]. ESs can guide conservation planning and "reveal potential spatial trade-offs and synergies between planning priorities" [64], as well as "assess[ing] different alternatives for the spatial planning of GI and ecosystem restoration, based on the ecosystems' potential to generate services" [61]. These GI proposals served to address a range of planning issues, showing their potential to better target the matters that constitute the different planning phases. However, the adoption of GI in planning instruments (i.e., plans or programmes) by administrative bodies is rather limited.

The last purpose assigned to ESs as knowledge support for GI development is strictly connected to the research question (Q3) "Is there a GI strategy based on ESs?", to which an answer has already been provided.

Further considerations are put forward in Section 3.3.

\subsection{Planning Type, ESs Categories and ESs Mapping}

In addition to the first group of research questions (i.e., Q1, Q2 and Q3), three other issues were addressed in the study:

1. Planning type:

The results seen in Figure 3 show the ten different types of planning included in the articles. A unique planning type was associated with each article by selecting the one explicitly mentioned in the paper. Only three articles did not refer to a specific planning type because they were literature reviews or opinion papers. In the other articles, spatial planning was the most prevalent (used in 26 articles) as was marine and coastal spatial planning (used in seven of the 26 articles), followed by urban planning (used in 19 articles), and land-use and landscape planning (used in nine articles each). Other types of planning were considered (i.e., conservation, participatory, regional, scenario, and territorial planning), but in only a limited number of articles. The predominance of spatial planning in ES-related research may indicate greater awareness of ESs dynamics at that level, in light of the fact that the proper functioning of ecosystems depends on earth system processes and is delimited by the biophysical properties and condition of an area, rather than any administrative boundaries. Spatial plans are key policy instruments for coordinating human activities and minimising their negative impact on natural and land systems [65]. Urban planning often suffers from a dearth of data availability and relies on coarser-grained ESs information, which may not provide reliable support for decision-making [66].

The last two aspects considered in the literature review (i.e., ESs category and mapping) are based on case-study research developed at different scales (urban, provincial, regional or national). Of the total 70 articles, 60 include case studies from 49 countries around the world, prevalently European ones (with Spain producing the most, followed by Italy and Germany) (Figure 4). 


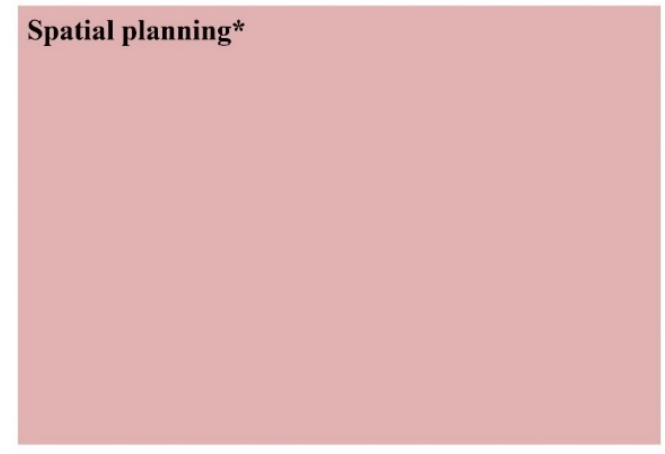

Urban planning
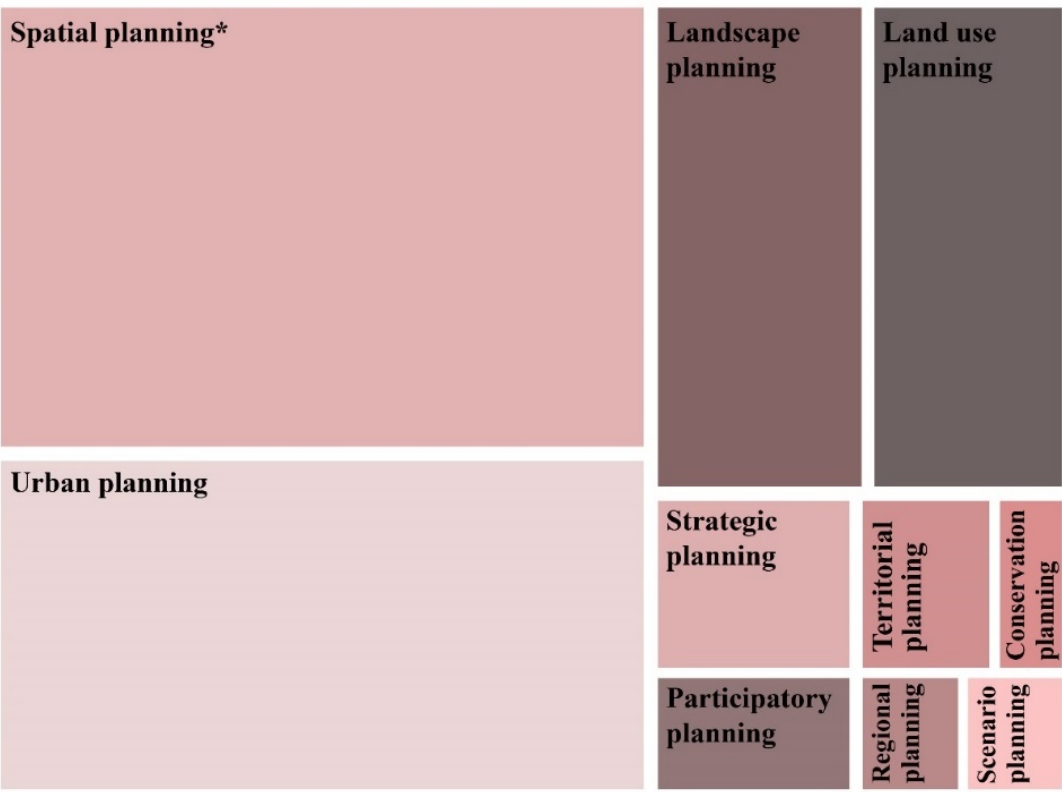

Figure 3. TreeMap of the distribution of the planning types considered in the literature review. (The figure was developed using "RAWGraphs", a web interface to create custom vector-based visualisations, and refined with Adobe Illustrator 2021 (Adobe Systems Inc., San Jose, CA, USA)). * Spatial planning includes marine and coastal spatial planning.

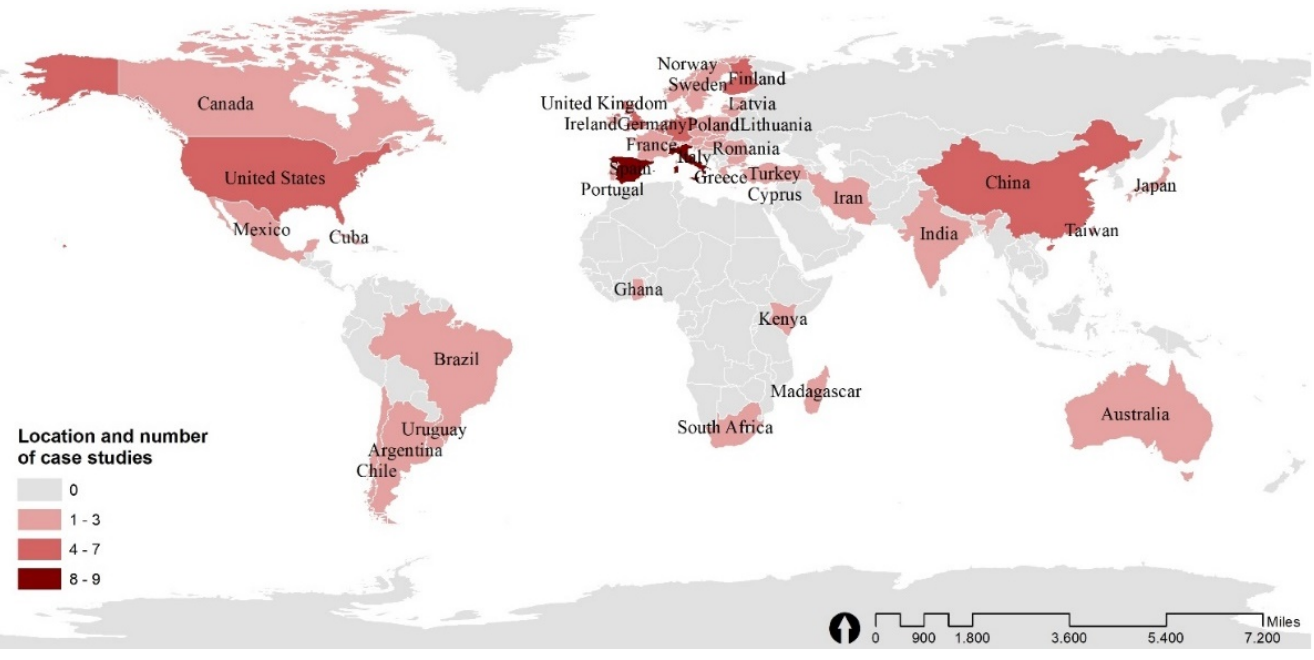

Figure 4. Location and number of case-study research papers considered in the literature review. (The figure was developed using Esri ArcMap 10.8.1).

\section{Categories of ESs:}

Of the research papers based on case studies, 32 articles incorporate an assessment of the ESs involved, often in terms of spatial distribution. The majority of the articles (17 in total) include all categories of ESs (regulating, provisioning and cultural) [12], with nine articles dedicated to just two categories of ESs (four on regulating and provisioning services, three on regulating and cultural services, and two on provisioning and cultural services) and five papers considering only a single category of ESs, with a preference for regulating ESs. In the research papers in which a GI is provided, all categories of ESs are deemed to fulfil the multifunctional principle of GI.

Combining the planning type with the category of ESs assessed in the articles brings to light certain considerations (Figure 5). First of all, it is possible to argue that the multifunctional evaluation of ESs is now a consolidated common approach to all planning 
types (among the many: $[24,41,52,67])$. The papers dedicated to evaluating a single category of ESs are now limited in number (five, e.g., [68,69]) which often investigate multiple types of ESs belonging to the same category. For example, $\mathrm{Xu}$ et al. [68] consider cultural ESs but divided into spiritual and aesthetic values, social relations, sense of place, recreation, and cultural heritage values. Or Bai et al. [69] focused on regulating ESs divide into carbon sequestration, water conservation, nitrogen retention and soil retention. Most articles combine multiple ESs and evaluate their trade-offs, which is currently the main challenge being addressed in most research in the field (e.g., [41,53]). Spatial planning seems to be the favoured planning type for such studies (followed by urban landscape and land-use planning), as evidenced by a substantial number of publications dedicated to the interaction between multiple ESs (e.g., [59,70]). However, landscape planning has several studies focused on one type of ES; many of these deal with cultural ESs, likely due to their greater ability to inform the landscape planning process as to the multiple values (both utilitarian and otherwise) that stakeholders assign to landscapes, especially by eliciting those social values that are often ignored by biophysical and economic ESs assessments [71]. This result is also in line with Englund et al. [72], suggesting that whilst in individual studies, cultural ESs are more often assessed at the landscape scale, while provisioning and regulating ESs are more commonly mapped at larger scales (regional or subnational). The extension of the landscape scale can vary in character and size and range of the biophysical and anthropogenic processes driving the processes (or services) under study $[73,74]$.

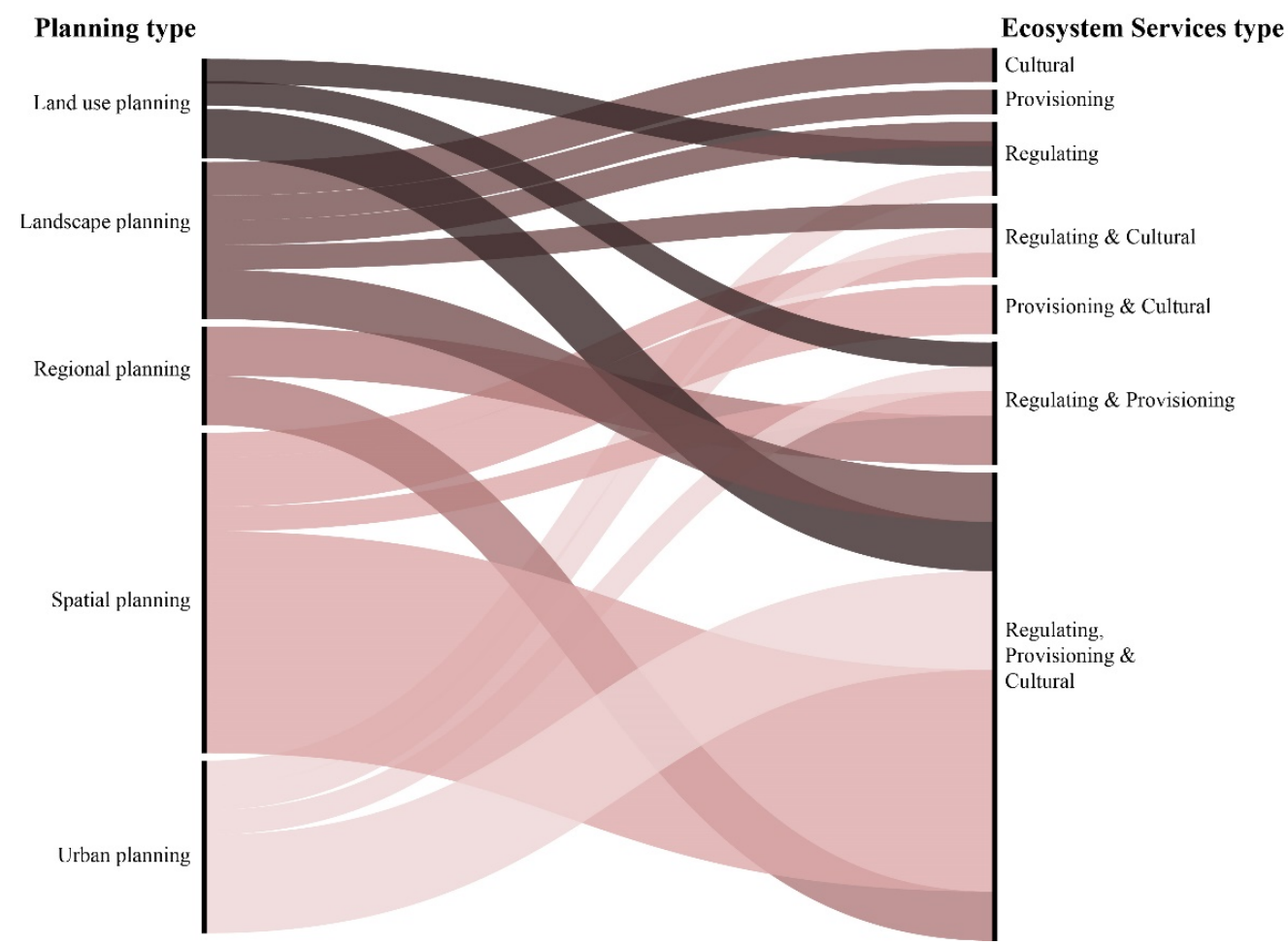

Figure 5. Alluvial diagram showing the relation between planning type and the ESs category considered in the articles. (The figure was developed using "RAWGraphs", a web interface to create custom vector-based visualisations, and refined with Adobe Illustrator 2021 (Adobe Systems Inc., San Jose, CA, USA)).

Urban planning explores regulating ESs, either in combination with other ESs or on an individual basis, considering their impacts on the provision of urban ESs, including microclimate regulation, air purification, noise reduction and runoff mitigation [28], all of which are essential for improving well-being and liveability for citizens. 


\section{ESs mapping:}

Considering the 32 articles with case studies that incorporate an ESs assessment, 26 of these provide an ESs mapping showing the consistent use of spatial mapping to represent an ESs dynamic, especially those dealing with multiple ESs. The multifunctionality of the ESs approach in the increasingly common use of combined maps demonstrates the close link between provisioning, regulation and cultural services. Additionally, cultural ESs are now extensively assessed through mapping, as opposed to in the past, when rapid quantitative mapping was not adequately suited to the complexity of cultural ESs, which require a combination of knowledge and methods (including qualitative methods) from different disciplines (largely environmental sciences, but also psychology, anthropology, and other social sciences) [28]. A handful of the papers dedicated to provisioning services have opted for types of assessment other than mapping. The most common of these is economic evaluation, which focuses on the assignment of a monetary value to ESs, whilst others are dedicated to presenting a methodological approach that explains the correct procedure to follow for an effective ESs assessment, and yet others consider ESs through the lens of stakeholder engagement during a participatory activity (Figure 6).

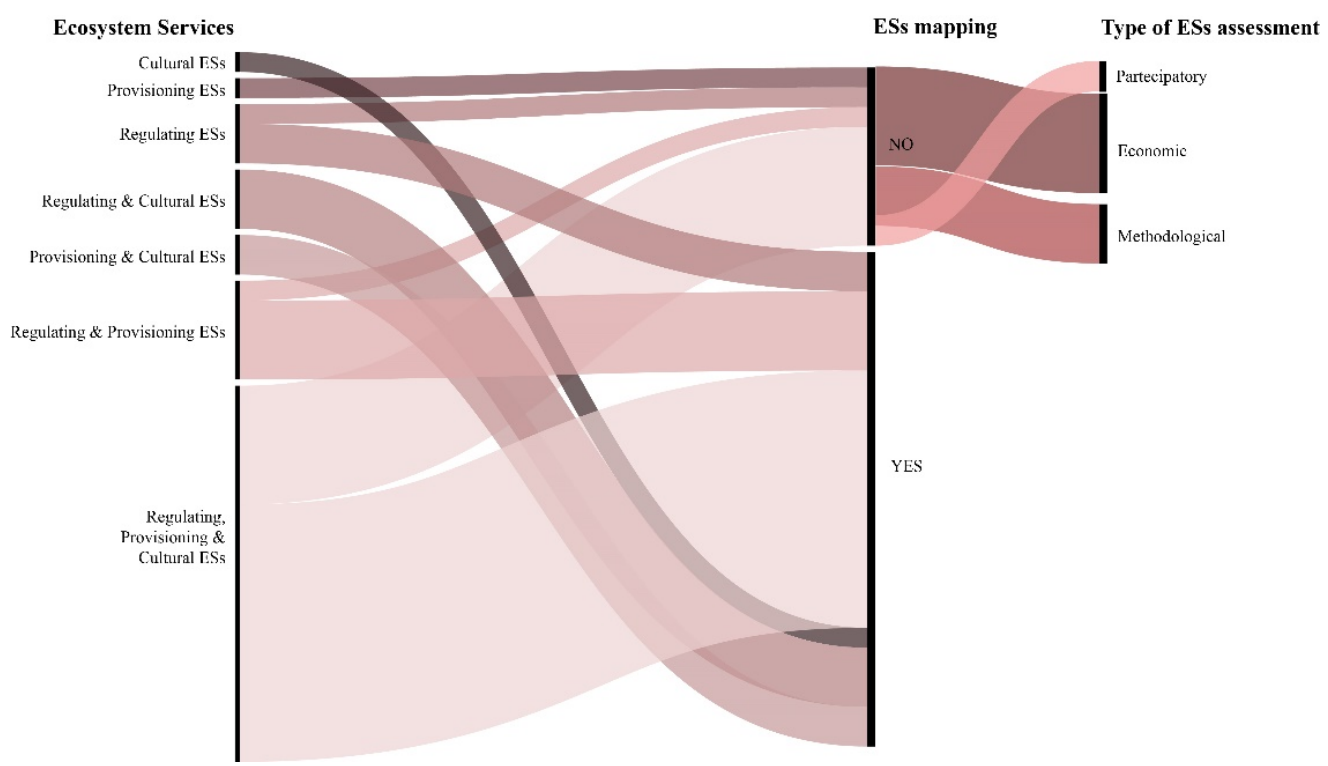

Figure 6. Alluvial diagram showing the relation between the ESs category considered in the research articles, the availability of ESs mapping, and the type of ESs assessment carried out in the absence of mapping. (The figure was developed using "RAWGraphs", a web interface to create custom vector-based visualisations, and refined with Adobe Illustrator 2021 (Adobe Systems Inc., San Jose, (A, USA)).

\subsection{ESs Integration in Planning: Some Best Practices from the Literature Review}

A review of the 70 articles considered for this study reveals a limited and fragmented integration of ESs into the planning process. Notable advances have been made in adopting ESs in urban and territorial plans by Spanish studies, and three, in particular, contain some highly innovative ideas.

The already mentioned research paper dedicated to the province of Barcelona includes a huge number of spatial indicators in an effort to demonstrate territorial multifunctionality and select strategic areas for GI planning based on biodiversity, ecosystem functions, and ESs supply and demand. The spatial indicators for ESs supply cover the ESs categories (regulating, provision and cultural) and they were combined with ESs demand for developing strategic areas of GI planning. The ESs and GI were developed to be implemented into landscape planning in the province of Barcelona with a view to supporting municipal land-use planning. As the study states, "the cartographic data of this study is already 
used at municipal scale for the proposal of Local GI by including it within the Municipal Urban Development Plans (POUM) - in municipalities of the Province of Barcelona-and it represents the framework for planning and managing the undevelopable land" [34]. The research adopts a cross-scale approach demonstrating that, at the urban scale, the results "allow planners to make better decisions, once the ESs supplied by the core city and the hinterlands are known" [34]. Urban green spaces acquire new values to improve "ecological connectivity, pollination and biodiversity and bring benefits to local communities" [34] and should be improved at a smaller scale. The results regarding the strategic areas for GI planning "can orient planners to better shape and prioritise areas for GI conservation, management or restoration" [34]. The cross-scale approach was considered to support planners first and foremost, rather than decision-makers, who can only be advised by the former; planners thus have a clear strategy to follow as a guide to sustainability.

The second article, which concerns the Basque Country, adopts an ESs approach to spatial planning through the co-creation of a knowledge process within the community of practices, providing an ideal comprehensive framework for facilitating planning and development decisions in all sectors, at all scales, and across administrative boundaries [24]. Amongst the outcomes of the co-creation of the knowledge process was a regional GI proposal, formulated by identifying the multifunctional areas that provide multiple ESs, as well as a practical guide to formulating spatial and urban planning programmes using ESs. An ESs assessment was included in spatial planning actions at different administrative levels and regarding the three ESs categories (provisioning, regulating and cultural), as mentioned in the paper: "(1) to establish criteria for the Renewed Uses and Management Master Plan (UMMP) for the Urdaibai Biosphere Reserve; (2) to establish criteria for the Renewed Partial Territorial Plan (PTP) for the Bilbao Metropolitan Area; (3) to identify the components that may form part of the GI of the Basque Country; and (4) to include ESs and GI in the Renewed Spatial Planning Guidelines (SPGs) of the Basque Country approved in 2019 (Decree 128/2019, of 30 July)" [24]. The results of this ESs assessment were included in the GI proposal for the Bilbao Metropolitan Area and the analysis carried out for the revised PTP.

Finally, the methodological approach used in the paper developed in the Galicia region shows how ESs assessment can be incorporated "both in spatial planning of GI and in land management [ ... ] the results of ESs assessment can be applied in multiple land management or planning processes, from protection of core areas of GI to ecosystem restoration, identification of compatible land use options, evaluation of current or future land policies, allocation of resources for environmental protection or restoration, analysis of alternative locations for projects or activities, etc." [59]. ESs can be integrated into the entire planning process, i.e., at each step of the procedure.The ESs assessment includes provisioning, regulating and cultural services and it was carried out at the landscape scale, but "can be applied in other regions at different scales, from municipal to national or international level, and for multiple purposes, because it is based on several key issues potentially replicable in any case" [59]. As such, ESs are considered as a means of deploying a multifunctional GI for the Galicia region, as well as of addressing and resolving some of the various issues that arise during a planning process. One such example would be ESs helping planners to understand how each part of a region provides each service, as well as assisting decision-makers and policymakers with land management. Although the research was supported by Galicia's Regional Ministry of Environment and Planning-the Xunta de Galicia (Spain) —it is not explicitly mentioned whether or not the results of the Galicia regional administration's research were adopted, so it is assumed that the integration process is still ongoing.

As previously mentioned, the other papers included in the literature review address the issue of ESs from various angles: some promoting assessments using innovative techniques and experimental methodologies to integrate them in a multifunctional way, others focusing on how ESs can be used in certain specific steps of the planning process-mostly the feasibility, alternative scenarios and implementation phases-whilst yet others encour- 
age the use of ESs for GI design, detailing the methodology and making GI support for planning functional and easily comprehensible. A few experiments were carried out during the planning process and working closely with decision-makers, but the administration ultimately did not implement the results. Any integration is often limited to the cognitive framework established in the preparatory phase of the planning process.

\section{Discussion}

\subsection{Main Outcomes of the Literature Review}

Considering the results derived from the literature review, certain issues cast light on several limitations of proposals for the integration of ESs into the planning processes that are strictly connected to procedural aspects of planning practices.

First of all, the often-mentioned acknowledgement of the importance of ESs to supporting the decision-making process and producing an environmentally oriented planning tool that is based on ESs knowledge requires the concept of ESs and information about them to be of interest to planners and decision-makers.

The tools of knowledge and practical expertise are prerequisites for effectively supporting planning practices $[21,75,76]$, making the added value of ESs for planning purposes evident. Beyond the possible integration of ESs proposals into planning, more studies are needed on what information and requirements planners and decision-makers demand when adopting ES-based approaches to planning, and more experiments are needed to show how ESs can be integrated into the existing decision-making structures of planning instruments. Otherwise, proposals for ESs integration remain nothing more than a theory that does not effectively engage with planners' real needs to address planning purposes by means of a specific planning instrument.

As such, more knowledge on how a planning process works is needed to make the ESs concept useful for addressing planning purposes. Most actual proposals for integrating ESs into the planning process do not consider how a planning instrument works or planners' needs, and instead mainly focus on providing new information and new knowledge without questioning their usefulness for planning purposes.

Planning practice does not require extremely detailed environmental information; it only necessitates data that is substantial and reliable enough to serve as a basis for decision-making. In that regard, specific studies have highlighted how it is possible to integrate ESs knowledge into instances of practical spatial planning, using it throughout the entire decision-making process [77]. Many advances have been made on mapping ESs, passing from an approach often sectorial and related on a single ES to the use of multifunctional mappings that allow for a better "dialogue" with planning tools facilitating their integration and use for planning purposes.

The integration of the ESs concept into planning requires operationalising them in each phase of the planning process making it evident how ESs can support the formulation of strategies and choices to effectively raise awareness of the value of natural capital and its implications on quality of life and well-being.

Another issue that emerges from the literature review concerns the use of ESs for the deployment of GI. Besides the three successful ES-based GI integrated into the planning process (as explained in Section 3.1, heading 5, and in Section 3.3), the other articles show the potential for GI to facilitate the integration of ESs into planning. What is missing from some of them is a discussion of the multi-scalarity of GI. Following Benedict and McMahon [78], Hansen and Pauleit [79], and Kambites and Owen [80], GI is based on five main principles: (1) integration: considering the grey-green combination of GI; (2) multifunctionality: GI includes the ecological, social and economic/abiotic, biotic and cultural functions of green spaces; (3) connectivity between green spaces; (4) a multi-scale approach spanning all levels, from the individual to the scales of community, region, and state; (5) a multi-object approach including different types of (urban) green and blue spaces.

Although some GI principles have been studied extensively—specifically, the multifunctionality of GI allowing for the development of strategies based on the provision of 
multiple ESs, as well as for ESs assessments that include all categories of ESs (see Section 3.2, heading 2)-the multi-scalar aspect of GI remains only superficially investigated.

This was also evident in the analysis of planning type and ESs mapping, with most articles adopting the spatial scale as the most relevant arena for decision-making to affect ESs $[45,49]$, but in order for GI to be effectively deployed, a multi-scale or cross-scale assessment is required. Using a multi-scale approach allows us to assess ESs at a different spatial scale and according to the most suitable scale of representation for any given phenomenon. The multi-scale approach also includes a cross-scale concept in the form of the interaction between various scales during the analysis for a given result. A cross-scale study is, by definition, a form of multi-scale study $[8,81]$.

The "multiple scales" of GI are treated differently in each of the various planning families found worldwide [77]. The multi-scale spatial dimension is based on the physical (spatial) and "functional connectivity between different areas at various spatial levels (local, regional, national, international)" [82]. The added value of the multi-scale assessment of ESs for the deployment of GI is made clear in Basnou et al. [34], demonstrating the utility of ESs assessment when planning for GI if "it can be applied at various spatial scales, offering at the same time simple and clear spatial information, easily understood and integrated into different plans". Adopting a multi-scale approach allows planners to respond to the various challenges that planning is faced with, generally involving dynamics that exist and require a cross-analysis at different scales. One example is the issue of ecological connectivity, which necessarily requires a regional assessment that allows for downscaling to the local level to define greening strategies that involve smaller patches of urban greenery (e.g., pocket parks or urban gardens) as a way of improving biodiversity and benefitting local communities.

Lastly, any proposal to increase the consideration of natural capital in planning through the ESs concept as a means of better addressing planning aims cannot exist separately from the Strategic Environmental Assessment (SEA), an instrument intended to guarantee a high level of environmental protection in drafting plans and programmes. The SEA is inextricably bound to sustainability efforts as it establishes environmental protectionrelated objectives, and therefore acts as a sustainability-oriented plan which becomes part of the planning process itself [83]. Moreover, the potentially limited environmental knowledge shown by planners-as evidenced, for example, by Calzolari et al. [84] suggesting that "soil is perceived by city planners as a mere supporting platform" - necessarily requires a greater degree of synergy with the SEA, which is put under strain by the dual task of compensating for any gaps in knowledge whilst also maintaining the high environmental performance of the planning instrument: its primary purpose.

In this regard, the SEA provides an opportunity to formally mainstream ESs into decision-making processes and planning. The objective of achieving improved environmental protection in planning must necessarily first pass through the SEA step, as this serves to direct and support the planning process. Unfortunately, it is very often the case that the two tools (SEA and planning) are kept separate, with the roles and aims assigned to them left unclear, resulting in the risk of confusing tasks and objectives. In the articles reviewed, the SEA is not sufficiently considered, emphasising the separation between planning and the SEA, with their limited interaction becoming even more evident.

\subsection{Limitations of the Study}

This study is not without its limitations, and these partly depend on the parameters set for the literature review (i.e., the combination of keywords, the choice of years, and the selection of peer-reviewed scholarly literature platforms), which are arbitrary and could limit the inclusion of other articles that may prove interesting for the aims of the research. The research methodology has consciously limited the selection of articles, with an attempt to focus on the quality of the content (with explicit reference to ESs and Planning in the title) over the number of articles investigated. 
A possible development could be integrating new keywords as parameters for the literature review. For example, a possible topic to be included could be the ESs mapping to verify how it could support the ESs integration in planning, or the SEA focusing on the ESs role in developing this assessment for planning purposes, or the GI and climate change relationship.

Moreover, the literature review is based only on the data, information and content included in the articles themselves, without further specific in-depth studies. For instance, the case studies mentioned as examples of integrating ESs into planning through the adoption of a specific plan or programme are limited to the articles that explicitly included this information; however, it is entirely possible that this integration may also have occurred in many other studies, even if it was not mentioned in the article.

\section{Conclusions}

The research paper conducts a literature review aiming to understand what purpose(s) is/are assigned to ESs in the planning process and, consequently, why planners should adopt ESs-in other words, what added value ES-based planning could offer. The results demonstrate an increasing consideration of ESs as a means of supporting the planning and decision-making process, highlighting the presence of multiple purposes assigned to them. Despite a growing body of research demonstrating the potential and opportunities in adopting ES-based planning, instances of the thorough integration of ESs into planning are still limited. Some significant recent examples have demonstrated how ESs assessment could support the multi-scalar deployment of GI, facilitating their integration into planning. The multi-scale spatial dimension of GI allows for some important challenges being faced by planning to be addressed, making ESs functional to the needs of planners and decisionmakers. The operability of ESs requires more extensive investigation in further studies to show how ESs can be integrated into the existing decision-making structures of planning instruments. In addition, more practical experiments on how a planning process works are needed in order to operationalise the ESs concept for planning purposes, avoiding proposals that do not fit with planning requirements, aims and purposes. Finally, the role of the SEA is still marginal and too divorced from planning; indeed, it should, on the contrary, be the framework within which ESs find a real application in the planning process, ensuring that conscious choices are made to potentiate the human benefits of providing ESs.

Funding: This research received no external funding.

Institutional Review Board Statement: Not applicable.

Informed Consent Statement: Not applicable.

Data Availability Statement: Not applicable.

Conflicts of Interest: The author declares no conflict of interest.

\section{References}

1. Cortinovis, C.; Geneletti, D. Ecosystem services in urban plans: What is there, and what is still needed for better decisions. Land Use Policy 2018, 70, 298-312. [CrossRef]

2. Neugarten, R.A.; Langhammer, P.F.; Osipova, E.; Bagstad, K.J.; Bhagabati, N.; Butchart, S.H.M.; Dudley, N.; Elliott, V.; Gerber, L.R.; Gutierrez Arrellano, C.; et al. Tools for Measuring, Modelling, and Valuing Ecosystem Services: Guidance for Key Biodiversity Areas, Natural World Heritage sites, and Protected Areas; IUCN Library System: Gland, Switzerland, 2018.

3. Tengö, M.; Hill, R.; Malmer, P.; Raymond, C.M.; Spierenburg, M.; Danielsen, F.; Elmqvist, T.; Folke, C. Weaving knowledge systems in IPBES, CBD and beyond-lessons learned for sustainability. Curr. Opin. Environ. Sustain. 2017, 26-27, 17-25. [CrossRef]

4. UNEP-United Nations Environment Programme. Guidance Manual on Valuation and Accounting of Ecosystem Services for Small Island Developing States; UNON Publishing Service Section: Nairobi, Kenya, 2014; ISBN 9789280734072.

5. Teixeira da Silva, R.; Fleskens, L.; van Delden, H.; van der Ploeg, M. Incorporating soil ecosystem services into urban planning: Status, challenges and opportunities. Landsc. Ecol. 2018, 33, 1087-1102. [CrossRef] 
6. $\quad$ Spyra, M.; Kleemann, J.; Cetin, N.I.; Vázquez Navarrete, C.J.; Albert, C.; Palacios-Agundez, I.; Ametzaga-Arregi, I.; La Rosa, D.; Rozas-Vásquez, D.; Adem Esmail, B.; et al. The ecosystem services concept: A new Esperanto to facilitate participatory planning processes? Landsc. Ecol. 2019, 34, 1715-1735. [CrossRef]

7. Mascarenhas, A.; Ramos, T.B.; Haase, D.; Santos, R. Ecosystem services in spatial planning and strategic environmental assessment-A European and Portuguese profile. Land Use Policy 2015, 48, 158-169. [CrossRef]

8. Ronchi, S. Ecosystem Services for Spatial Planning. Innovative Approaches and Challenges for Practical Applications; Green Ener.; Springer International Publishing AG: Cham, Switzerland, 2018; ISBN 9783319901848.

9. De Groot, R.; Alkemade, R.; Braat, L.; Hein, L.; Willemen, L. Challenges in integrating the concept of ecosystem services and values in landscape planning, management and decision making. Ecol. Complex. 2010, 7, 260-272. [CrossRef]

10. Galler, C.; Albert, C.; von Haaren, C. From regional environmental planning to implementation: Paths and challenges of integrating ecosystem services. Ecosyst. Serv. 2016, 18, 118-129. [CrossRef]

11. Greiber, T.; Schiele, S. Governance of Ecosystem Services; IUCN: Gland, Switzerland, 2011; ISBN 978-2-8317-1427-1.

12. Haines-Young, R.; Potschin-Young, M.; Czúcz, B. Report on the Use of CICES to Identify and Characterise the Biophysical, Social and Monetary Dimensions of ES Assessments. Available online: https:/ / ec.europa.eu/research/participants/documents/ downloadPublic?documentIds=080166e5abaa617f\&appId=PPGMS (accessed on 9 June 2021).

13. Andersson, E.; Barthel, S.; Borgström, S.; Colding, J.; Elmqvist, T.; Folke, C.; Gren, Å. Reconnecting Cities to the Biosphere: Stewardship of Green Infrastructure and Urban Ecosystem Services. Ambio 2014, 43, 445-453. [CrossRef]

14. Gómez-Baggethun, E.; Gren, Å.; Barton, D.N.; Langemeyer, J.; McPhearson, T.; O'farrell, P.; Andersson, E.; Hamstead, Z.; Kremer, P. Urban ecosystem services. In Urbanization, Biodiversity and Ecosystem Services: Challenges and Opportunities: A Global Assessment; Springer: Amsterdam, The Netherlands, 2013; pp. 175-251, ISBN 9789400770881.

15. Woodruff, S.C.; BenDor, T.K. Ecosystem services in urban planning: Comparative paradigms and guidelines for high quality plans. Landsc. Urban. Plan. 2016, 152, 90-100. [CrossRef]

16. Tratalos, J.; Fuller, R.A.; Warren, P.H.; Davies, R.G.; Gaston, K.J. Urban form, biodiversity potential and ecosystem services. Landsc. Urban. Plan. 2007, 83, 308-317. [CrossRef]

17. Alberti, M. The Effects of Urban Patterns on Ecosystem Function. Int. Reg. Sci. Rev. 2005, 28, 168-192. [CrossRef]

18. Jansson, $\AA$. Reaching for a sustainable, resilient urban future using the lens of ecosystem services. Ecol. Econ. 2013, 86, 285-291. [CrossRef]

19. BenDor, T.K.; Spurlock, D.; Woodruff, S.C.; Olander, L. A research agenda for ecosystem services in American environmental and land use planning. Cities 2017, 60, 260-271. [CrossRef]

20. Hölzingera, O.; Tringhamb, N.; Graysonb, N. Multiple Challenge Map for Birmingham: Ecosystem Services Supply and Demand Maps. Appendix 2 to Birmingham's Green Living Spaces Plan 2013; Birmingham City Council: Birmingham, UK, 2013.

21. Albert, C.; Aronson, J.; Fürst, C.; Opdam, P. Integrating ecosystem services in landscape planning: Requirements, approaches, and impacts. Landsc. Ecol. 2014, 29, 1277-1285. [CrossRef]

22. Rall, E.L.; Kabisch, N.; Hansen, R. A comparative exploration of uptake and potential application of ecosystem services in urban planning. Ecosyst. Serv. 2015, 16, 230-242. [CrossRef]

23. Mascarenhas, A.; Ramos, T.B.; Haase, D.; Santos, R. Integration of ecosystem services in spatial planning: A survey on regional planners' views. Landsc. Ecol. 2014, 29, 1287-1300. [CrossRef]

24. Peña, L.; de Manuel, B.F.; Méndez-Fernández, L.; Viota, M.; Ametzaga-Arregi, I.; Onaindia, M. Co-creation of knowledge for ecosystem services approach to spatial planning in the Basque Country. Sustainability 2020, 12, 5287. [CrossRef]

25. Kabisch, N.; Qureshi, S.; Haase, D. Human-environment interactions in urban green spaces-A systematic review of contemporary issues and prospects for future research. Environ. Impact Assess. Rev. 2015, 50, 25-34. [CrossRef]

26. Piwowarczyk, J.; Kronenberg, J.; Dereniowska, M.A. Marine ecosystem services in urban areas: Do the strategic documents of Polish coastal municipalities reflect their importance? Landsc. Urban. Plan. 2013, 109, 85-93. [CrossRef]

27. Ronchi, S.; Arcidiacono, A.; Pogliani, L. Integrating green infrastructure into spatial planning regulations to improve the performance of urban ecosystems. Insights from an Italian case study. Sustain. Cities Soc. 2020, 53, 1-12. [CrossRef]

28. Gómez-Baggethun, E.; Barton, D.N. Classifying and valuing ecosystem services for urban planning. Ecol. Econ. 2013, 86, 235-245. [CrossRef]

29. Lennon, M.; Scott, M. Delivering ecosystems services via spatial planning: Reviewing the possibilities and implications of a green infrastructure approach. Town Plan. Rev. 2014, 85, 563-587. [CrossRef]

30. Ronchi, S.; Arcidiacono, A. Lessons from Italian Experiences: Bottlenecks, New Challenges and Opportunities. In Ecosystem Services and Green Infrastructure. Perspective from Spatial Planning in Italy; Arcidiacono, A., Ronchi, S., Eds.; Springer International Publishing: Cham, Switzerland, 2021; pp. 225-236, ISBN 978-3-030-54345-7.

31. European Commission. Building a Green Infrastructure for Europe; Publications Office of the European Union: Luxembourg, 2013.

32. Rouse, D.C.; Bunster-Ossa, I.F. Green Infrastructure: A Landscape Approach; American Planning Association: Washington, DC, USA, 2013; ISBN 9781611900620.

33. Matthews, T.; Lo, A.Y.; Byrne, J.A. Reconceptualizing green infrastructure for climate change adaptation: Barriers to adoption and drivers for uptake by spatial planners. Landsc. Urban. Plan. 2015, 138, 155-163. [CrossRef] 
34. Basnou, C.; Baró, F.; Langemeyer, J.; Castell, C.; Dalmases, C.; Pino, J. Advancing the green infrastructure approach in the Province of Barcelona: Integrating biodiversity, ecosystem functions and services into landscape planning. Urban. For. Urban. Green. 2020, 55. [CrossRef]

35. Stefanović, N.; Josimović, B.; Danilović Hristić, N. Models of Implementation of Spatial Plans: Theoretical Approach and Case Studies for Spatial Plans for the Special Purpose Area. In An Overview of Urban and Regional Planning Expected; Ergen, Y., Ed.; IntechOpen: London, UK, 2018; pp. 60-81.

36. Steiner, F. The Living Landscape. An Ecological Approach to Landscape Planning; Island Press: Washington, DC, USA, 2008.

37. Stoeglehner, G. Enhancing SEA effectiveness: Lessons learnt from Austrian experiences in spatial planning. Impact Assess. Proj. Apprais. 2010, 28, 217-231. [CrossRef]

38. Millennium Ecosystem Assessment. Ecosystems and Human Well-Being: Synthesis; Island Press: Washington, DC, USA, 2005.

39. Roy Haines-Young, P.M. Common International Classification of Ecosystem Services (CICES, Version 4.3); European Environment Agency: København, Denmark, 2013; pp. 1-17.

40. Khoshkar, S.; Hammer, M.; Borgström, S.; Dinnétz, P.; Balfors, B. Moving from vision to action- integrating ecosystem services in the Swedish local planning context. Land Use Policy 2020, 97. [CrossRef]

41. Karimi, A.; Yazdandad, H.; Fagerholm, N. Evaluating social perceptions of ecosystem services, biodiversity, and land management: Trade-offs, synergies and implications for landscape planning and management. Ecosyst. Serv. 2020, 45. [CrossRef]

42. Fossey, M.; Angers, D.; Bustany, C.; Cudennec, C.; Durand, P.; Gascuel-Odoux, C.; Jaffrezic, A.; Pérès, G.; Besse, C.; Walter, C. A Framework to Consider Soil Ecosystem Services in Territorial Planning. Front. Environ. Sci. 2020, 8. [CrossRef]

43. Friedrich, L.A.; Glegg, G.; Fletcher, S.; Dodds, W.; Philippe, M.; Bailly, D. Using ecosystem service assessments to support participatory marine spatial planning. Ocean. Coast. Manag. 2020, 188. [CrossRef]

44. Vergara, X.; Carmona, A.; Nahuelhual, L. Spatial coupling and decoupling between ecosystem services provisioning and benefiting areas: Implications for marine spatial planning. Ocean. Coast. Manag. 2020. [CrossRef]

45. Rozas-Vásquez, D.; Fürst, C.; Geneletti, D.; Almendra, O. Integration of ecosystem services in strategic environmental assessment across spatial planning scales. Land Use Policy 2018, 71, 303-310. [CrossRef]

46. De Meo, I.; Cantiani, M.G.; Ferretti, F.; Paletto, A. Qualitative assessment of forest ecosystem services: The stakeholders' point of view in support of landscape planning. Forests 2018, 9, 465. [CrossRef]

47. Turkelboom, F.; Leone, M.; Jacobs, S.; Kelemen, E.; García-Llorente, M.; Baró, F.; Termansen, M.; Barton, D.N.; Berry, P.; Stange, E.; et al. When we cannot have it all: Ecosystem services trade-offs in the context of spatial planning. Ecosyst. Serv. 2018, 29, 566-578. [CrossRef]

48. Wilkerson, M.L.; Mitchell, M.G.E.; Shanahan, D.; Wilson, K.A.; Ives, C.D.; Lovelock, C.E.; Rhodes, J.R. The role of socio-economic factors in planning and managing urban ecosystem services. Ecosyst. Serv. 2018, 31, 102-110. [CrossRef]

49. Cortinovis, C.; Geneletti, D. A framework to explore the effects of urban planning decisions on regulating ecosystem services in cities. Ecosyst. Serv. 2019, 38. [CrossRef]

50. Olander, L.P.; Johnston, R.J.; Tallis, H.; Kagan, J.; Maguire, L.A.; Polasky, S.; Urban, D.; Boyd, J.; Wainger, L.; Palmer, M. Benefit relevant indicators: Ecosystem services measures that link ecological and social outcomes. Ecol. Indic. 2018, 85, 1262-1272. [CrossRef]

51. Malmborg, K.; Enfors-Kautsky, E.; Queiroz, C.; Norström, A.; Schultz, L. Operationalizing ecosystem service bundles for strategic sustainability planning: A participatory approach. Ambio 2020. [CrossRef]

52. Van der Biest, K.; Meire, P.; Schellekens, T.; D’hondt, B.; Bonte, D.; Vanagt, T.; Ysebaert, T. Aligning biodiversity conservation and ecosystem services in spatial planning: Focus on ecosystem processes. Sci. Total Environ. 2020, 712, 136350. [CrossRef]

53. Peña, L.; Onaindia, M.; de Manuel, B.F.; Ametzaga-Arregi, I.; Casado-Arzuaga, I. Analysing the synergies and trade-offs between ecosystem services to reorient land use planning in Metropolitan Bilbao (northern Spain). Sustainability 2018, 10, 4376. [CrossRef]

54. Xin, Z.; Li, C.; Liu, H.; Shang, H.; Ye, L.; Li, Y.; Zhang, C. Evaluation of temporal and spatial ecosystem services in Dalian, China: Implications for urban planning. Sustainability 2018, 10, 1247. [CrossRef]

55. Perrotti, D.; Stremke, S. Can urban metabolism models advance green infrastructure planning? Insights from ecosystem services research. Environ. Plan. B Urban. Anal. City Sci. 2020, 47, 678-694. [CrossRef]

56. Cortinovis, C.; Geneletti, D. A performance-based planning approach integrating supply and demand of urban ecosystem services. Landsc. Urban. Plan. 2020, 201, 103842. [CrossRef]

57. Lin, Y.-P.; Chen, C.-J.; Lien, W.-Y.; Chang, W.-H.; Petway, J.R.; Chiang, L.-C. Landscape conservation planning to sustain ecosystem services under climate change. Sustainability 2019, 11, 1393. [CrossRef]

58. Lam, S.T.; Conway, T.M. Ecosystem services in urban land use planning policies: A case study of Ontario municipalities. Land Use Policy 2018, 77, 641-651. [CrossRef]

59. García, A.M.; Santé, I.; Loureiro, X.; Miranda, D. Green infrastructure spatial planning considering ecosystem services assessment and trade-off analysis. Application at landscape scale in Galicia region (NW Spain). Ecosyst. Serv. 2020, 43. [CrossRef]

60. Capotorti, G.; De Lazzari, V.; Al, M. Local Scale Prioritisation of Green Infrastructure for Enhancing Biodiversity in Peri-Urban Agroecosystems: A Multi-Step Process Applied in the Metropolitan City of Rome (Italy). Sustainability 2019, 11, 3322. [CrossRef]

61. Vallecillo, S.; Polce, C.; Barbosa, A.; Perpiña Castillo, C.; Vandecasteele, I.; Rusch, G.M.; Maes, J. Spatial alternatives for Green Infrastructure planning across the EU: An ecosystem service perspective. Landsc. Urban. Plan. 2018, 174, 41-54. [CrossRef] 
62. Cortinovis, C.; Geneletti, D. Mapping and assessing ecosystem services to support urban planning: A case study on brownfield regeneration in Trento, Italy. One Ecosyst. 2018, 3. [CrossRef]

63. Ramyar, R.; Saeedi, S.; Bryant, M.; Davatgar, A.; Mortaz Hedjri, G. Ecosystem services mapping for green infrastructure planning-The case of Tehran. Sci. Total Environ. 2020, 703, 135466. [CrossRef] [PubMed]

64. Meerow, S. A green infrastructure spatial planning model for evaluating ecosystem service tradeoffs and synergies across three coastal megacities. Environ. Res. Lett. 2019, 14. [CrossRef]

65. Albert, C.; Fürst, C.; Ring, I.; Sandström, C. Research note: Spatial planning in Europe and Central Asia-Enhancing the consideration of biodiversity and ecosystem services. Landsc. Urban. Plan. 2020, 196, 103741. [CrossRef]

66. Grêt-Regamey, A.; Weibel, B.; Bagstad, K.J.; Ferrari, M.; Geneletti, D.; Klug, H.; Schirpke, U.; Tappeiner, U. On the Effects of Scale for Ecosystem Services Mapping. PLoS ONE 2014, 9, e112601. [CrossRef] [PubMed]

67. Jaligot, R.; Chenal, J. Stakeholders' perspectives to support the integration of ecosystem services in spatial planning in Switzerland. Environment 2019, 6, 88. [CrossRef]

68. Xu, H.; Zhao, G.; Fagerholm, N.; Primdahl, J.; Plieninger, T. Participatory mapping of cultural ecosystem services for landscape corridor planning: A case study of the Silk Roads corridor in Zhangye, China. J. Environ. Manag. 2020, 264, 110458. [CrossRef]

69. Bai, Y.; Wong, C.P.; Jiang, B.; Hughes, A.C.; Wang, M.; Wang, Q. Developing China's Ecological Redline Policy using ecosystem services assessments for land use planning. Nat. Commun. 2018, 9, 3034. [CrossRef]

70. Drobnik, T.; Schwaab, J.; Grêt-Regamey, A. Moving towards integrating soil into spatial planning: No net loss of soil-based ecosystem services. J. Environ. Manag. 2020, 263. [CrossRef] [PubMed]

71. Van Riper, C.J.; Kyle, G.T. Capturing multiple values of ecosystem services shaped by environmental worldviews: A spatial analysis. J. Environ. Manag. 2014, 145, 374-384. [CrossRef]

72. Englund, O.; Berndes, G.; Cederberg, C. How to analyse ecosystem services in landscapes-A systematic review. Ecol. Indic. 2017, 73, 492-504. [CrossRef]

73. Crossman, N.D.; Burkhard, B.; Nedkov, S.; Willemen, L.; Petz, K.; Palomo, I.; Drakou, E.G.; Martín-Lopez, B.; McPhearson, T.; Boyanova, K.; et al. A blueprint for mapping and modelling ecosystem services. Ecosyst. Serv. 2013, 4, 4-14. [CrossRef]

74. Burkhard, B.; Maes, J. MappingEcosystem Services; Pensoft Publishers: Sofia, Bulgaria, 2017; ISBN 9789546428295.

75. Primmer, E.; Furman, E. Operationalising ecosystem service approaches for governance: Do measuring, mapping and valuing integrate sector-specific knowledge systems? Ecosyst. Serv. 2012, 1, 85-92. [CrossRef]

76. Opdam, P.; Nassauer, J.I.; Wang, Z.; Albert, C.; Bentrup, G.; Castella, J.C.; McAlpine, C.; Liu, J.; Sheppard, S.; Swaffield, S. Science for action at the local landscape scale. Landsc. Ecol. 2013, 28, 1439-1445. [CrossRef]

77. Di Marino, M.; Tiitu, M.; Lapintie, K.; Viinikka, A.; Kopperoinen, L. Integrating green infrastructure and ecosystem services in land use planning. Results from two Finnish case studies. Land Use Policy 2019, 82, 643-656. [CrossRef]

78. Benedict, M.A.; McMahon, E.T. Green infrastructure: Smart conservation for the 21st century. Renew. Resour. J. 2001, 20 , $12-17$.

79. Hansen, R.; Pauleit, S. From Multifunctionality to Multiple Ecosystem Services? A Conceptual Framework for Multifunctionality in Green Infrastructure Planning for Urban Areas. Ambio 2014, 43, 516-529. [CrossRef]

80. Kambites, C.; Owen, S. Renewed prospects for green infrastructure planning in the UK. Plan. Pract. Res. 2006, 21, 483-496. [CrossRef]

81. Scholes, R.; Reyers, B.; Biggs, R.; Spierenburg, M.; Duriappah, A. Multi-scale and cross-scale assessments of social-ecological systems and their ecosystem services. Curr. Opin. Environ. Sustain. 2013, 5, 16-25. [CrossRef]

82. Ahern, J. From fail-safe to safe-to-fail: Sustainability and resilience in the new urban world. Landsc. Urban. Plan. 2011, 100, 341-343. [CrossRef]

83. Geneletti, D. Reasons and options for integrating ecosystem services in strategic environmental assessment of spatial planning. Int. J. Biodivers. Sci. Ecosyst. Serv. Manag. 2011, 7, 143-149. [CrossRef]

84. Calzolari, C.; Tarocco, P.; Lombardo, N.; Marchi, N.; Ungaro, F. Assessing soil ecosystem services in urban and peri-urban areas: From urban soils survey to providing support tool for urban planning. Land Use Policy 2020, 99, 105037. [CrossRef] 